\title{
Diaspora, Material Life and Cultural Identity: Chinese Women Writers in Taiwan during the 1950s
}

\author{
Ya-Shu Chen \\ Department of Foreign Languages and Literatures, Chung Hua University; Hsin-chu, Taiwan
}

Received March 17, 2020; Revised April 24, 2020; Accepted May 20, 2020

Copyright $(2020$ by authors, all rights reserved. Authors agree that this article remains permanently open access under the terms of the Creative Commons Attribution License 4.0 International License

\begin{abstract}
A large number of mainlanders were forced to move to Taiwan with the KMT government in 1949. This group of Chinese mainlanders was mostly servicemen, government employees, and teachers; their composition differed tremendously from local Taiwanese. Such differences have been the historical and social origins of ethnic conflicts in Taiwan accordingly. It is found that although gender issues are important, it is not necessary and sufficient in the relations among ethnic groups in particular. Female mainlanders, due to their everyday life interactions with local people, had a much closer contact with local Taiwanese. The closer contact generated a higher local identity than that of their male counterparts. This paper therefore aims to explore the dynamic process between one's everyday life and cultural identity. Through a series of textual analyses of the work of female main land writers, the present author attempts to inquire into the material basis of cultural identity through aspects of social life, namely food, clothing, residence, social networks, transportation and travel, education, and entertainment. This paper would also discuss the theoretical implication in a diaspora space.
\end{abstract}

Keywords Chinese Diaspora, Material Life, Cultural Identity, Women Writers, Taiwan

\section{Migration or Diaspora?}

After the KMT govern ment moved to Taiwan in 1949, more than 400,000 Chinese mainlanders came with it. Most of the mainlanders who arrived at Taiwan were governmental employees, high ranking military officers and soldiers, teachers, and writers. The majority of these people obviously were grouped as the ruling class, or the cultural elites, especially the latter two groups of people. They were mostly born in the early 1900s, college graduates, and few of the meven studied overseas, and had master's or Ph.D. degrees. Already closed to their late thirties, quite a few of them had already had important governmental positions prior to their coming to Taiwan. Therefore, after these elite mainlanders came here, they continued to retain their positions or even be given higher positions in the central government, military, or schools of all levels. These "intruders," precisely due to the fact that they belonged to the ruling class, and their "wishful" nostalgic, home-bounding policies, had instigated much tension and conflict between the local Taiwanese and the elite mainlanders in everyday life interactions ever since they came.

As early as the 17th century, Chinese, especially from Guangdong and Fujian, began to move to Southeast Asian countries and Taiwan, and Chinese immigrants of South Korea came from Shandong. These immigrants were almost all economic immigrants. The main reason for moving out is that it was not easy to live in their original places of residence, so they were looking for new life possibilities. The relationship between these immigrants and their immigration countries vary from country to country. Chinese immigrants to Thailand were almost completely integrated into the local community, but Chinese immigrants to Malaysia and Indonesia were very isolated from the local commun ity. Chinese immig rants to Taiwan, also so known as mainlanders, rushed the local indigenous people to the mountains and became the new owners of the island [1]. In spite of these differences, basically all the immigrants have maintained close ties with their hometowns in China, and even often lived back and forth between the two places. However, these immigrants gradually settled down and became veritable "settlers." From this perspective, Chinese immigrants from the 17 th century to the mid-20th century belonged to the traditionally so-called "international migration" category, and they belonged to a different category from the concept of diaspora [2].

However, the nature of the Chinese migrating to Taiwan in the 1950s was completely different, and this 
migration phenomenon is closer to diaspora rather than the traditional immigration concept. The concept of diaspora originally meant that the Jews were forced to exile from Babylon in $586 \mathrm{BC}$. But the word used in the discussion at that time was mainly dispersal. Until $70 \mathrm{AD}$, the Jews were driven out of Jerusale m by the Romans, and after being exiled by various countries, the word diaspora gradually became the specific mark of the Jews [3], and its meaning gradually fixed, mainly including the following important phenomena: 1 . They were forced to leave their homes and relocate to other places, and often suffered from major psychological trauma; 2. Frequently looking back on their homes, they harbored a strong nostalgia for the homes that could not be forgotten; 3 . They had a strong sense of loss; 4 . They established close social networks with each other in different places and retained their own cultural and tradition; 5. Living in different yet "strange" places, the discrete must keep a certain degree of relationship with the local residents, but unity and inwardness within themselves also easily made their relations with local residents tense and hostile. [4].

Judging by the above criteria, the group of people who emigrated to Taiwan from China in the 1950s is obviously very different from the Chinese immigrants who immigrated to Southeast Asia in the past. This group of immigrants suffered the huge trauma of the Chinese Civil War, was defeated by the Communist Party, and then retreated to Taiwan. However, they remained determined to fight against Communist China and return home victoriously. Therefore, they frequently looked back and established close links with each other and their lifestyle was separated from that of local residents. These phenomena are very different from Chinese immigration experiences in the past, but closer to the Jewish diaspora experience. Of course, with the passage of time, the counter-attack on the mainland was obviously hopeless. The second generation of mainlanders has remained nostalgic because of the influence of their parents, but they have also been gradually localized, and their lifestyle gradually changed. The third-generation mainlanders and their descendants are basically localized. It is thus difficult to apply the term diaspora to them. But for the first and even second-generation, diaspora best captures the mood and experience of this group of Chinese.

However, the diaspora experience of mainlanders in Taiwan is unique. Generally, the discrete people are a minority, being marginalized. They are often excluded by the local society. However, main landers in Taiwan were not the same. Although these people were still a minority in number, they built an independent and even authoritarian government politically, with huge powers and resources. In terms of education and culture, these people were even more elite, which was very different from the general public in Taiwan in the 1950s. As Tabori points out:

The 20th century Chinese history produced a huge society-in-exile, among which the regime established in Taiwan was the largest, most prosperous, and most important one. This is one of few cases in modern history where a core regime left the original land, surviving as an exile government, and could still establish an authoritarian government [4: 4].

In this sense, the diaspora experienced by Taiwan mainlanders is different from that of other ethnic groups. Facing the local society of Taiwan, this group of cultural and political elites showed a strong sense of superiority, interacting less with local people intentionally or unintentionally, establishing a denser social network with each other, and showing a strong nostalgic character identified with their original hometowns. They almost ignored the existence of the local culture, and rarely mentioned it. Even if they occasionally mentioned local culture, they often displayed negative images and even scornful attitudes. Such attitudes toward local people are rare in ordinary diaspora experience.

But the above description is not always the case. The gender of a discrete person, as well as his/her physical environment and social life, also have a considerable impact on his/her identity. Generally speaking, because of the needs of life, women have more opportunities to contact the local people, and it is easier to raise their feelings for the local culture, so their identity is more diverse, not limited to their original identity. Some of them, because of living in remote areas, did not find it easy to connect with their hometown communities, and therefore it was difficult for them to maintain their hometown lifestyle. These people were also forced to have more contact with local people and adopt the local people's lifestyle. As a result, a more complex identity is formed. The main purpose of this study is how a discrete woman's local experience, especially her material life, such as the decoration of her home, diet, social networking, and entertainment, etc., affects her cultural identity. I will focus on and analyze the texts of Taiwan mainland women writers in the 1950s to support my research.

\section{Diaspora and Cultural Identity}

The issues of separation and identification are complex and vary greatly over time. In terms of the dispersion of the mainland Chinese, before the mid-1960s, they basically moved to Southeast Asia, Taiwan, Hong Kong and other countries, and a few moved to North A merica, Europe, and Australia. However, after the mid-1960s, Taiwan, Hong Kong, and Southeast Asia all saw a large moving-out population. The areas that these people moved in were mainly Europe, the United States, and Australia. Many discrete people even made the second and third moves, so the issues of separation and identification became complicated and diversified. At this stage, the 
identification of discrete people has often shifted between two or even more countries, and they showed less attachment and nostalgia for their motherland. Many people have begun to use "transnationalism" to form the cultural identity of the discrete during this period [1].

The period this study deals with falls from the 1950s to the $1960 \mathrm{~s}$. At this time, the diaspora problem is still very simple. For the purposes of this study, the object of the study is the Chinese who emigrated to Taiwan in 1949. The reason for the removal is also consistent with the traditional diaspora theme, that is, a group of people with traumatic experience are forced to leave their places of residence and move to another place (Taiwan). Although Taiwan was a province of China at that time, because the Taiwanese experienced Japanese rule for half a century until WWII, the language, political culture, and even daily habits, including clothing, were very different, triggering many political conflicts between the two ethnic groups, coupled with the differences in terroir, climate, and terrain When these Chinese people came to Taiwan, they were like Jewish discrete people, separated from the local residents. In addition to forming their own intimate networks, they fell into infinite thoughts of their home country. They were looking forward to returning to the embrace of their home country one day, showing a typical diaspora complex [4].

However, the major difference between the Chinese discrete and the Jews in this study is that the Jews belong to ethnic minorities in all places of residence, and are discriminated and excluded by local residents. This is also the main reason why the diaspora complex is formed. However, in this study, the discrete people from China appear to be "foreign" rulers. In addition to establishing an authoritarian government and possessing strong political power, they were richer and more powerful at all levels of society and culture than the local Taiwanese. Under these circumstances, one cannot help asking, how were the Chinese discrete in Taiwan different from the traditional immigrants? Apart from endless nostalgia and the prospect of returning home, what can we learn from the Chinese immigrants? This is the focus of this study.

Most studies the Chinese immigrants in Taiwan during the 1950s have a common conclusion: the Chinese discrete not only have a strong Chinese cultural identity, but also establish a dominant culture; that is to say, even local Taiwanese undoubtedly accept Chinese identity. Moreover, in addition to having a compulsory element in the beginning, this identity finally became a moral and cultural form of voluntary acceptance of leadership of mainlanders [5]. At that time, the Taiwanese were not familiar with Chinese writing because they had been ruled by the Japanese for 50 years. In addition, various cultural media were monopolized by main land rulers. Therefore, the entire cultural field was dominated by them. This group of Chinese cultural elites incorporated China's national policy into their discourse and mainly emphasized counterattack and restoration of China, rescuing their fellows in China. They were not interested in what happened in Taiwan and did not even notice the existence of surrounding people. David Der-wei Wang even described the literature of this period as "post-loyalist literature," arguing that these elites acted and wrote like literati of the former dynasties, completely immersed in their past world, and seemed to have nothing to do with what was happening in the new dynasty, so he called them "post-loyalists"[6].

However, some recent studies have shown that this kind of cultural dominance or post-loyalist views cannot describe the complicated conditions of the literature at that time, and the cultural identity of these main land writers has also been simplified. Fan Mingru's insightful analyses of the first-generation mainland women writers are the most important pioneering such works ever available. After analyzing extensively these women writers' early works, Fan concluded that they had already formed an ethnic identify to a greater extent after they "traveled" to Taiwan, despite the fact that they could not cut off their original, emotional ties with their native land. Different from traditional chronological readings of texts; i.e., one's ethnic identity is resulted from one's growing experiences, Fan uses Susan Friedman's theory of spatial reading to examine these writers' works [7].

Friedman's theory of spatial reading proposes that when a person travels/moves to a different place, due to cultural clashes, new values, be it morally or culturally, will be formed out of such strange clashes. Consequently, awakened by such a new cultural shock, a new local identity could emerge. Take home-returning as an example. According to Friedman, a person's new local or ethnical identity comes from his/her traveling [8]. It means traveling/moving represents not only a change of space, but also a new cultural encountering. Fan analyzes texts written by the first-generation mainland women writers to warrant Friedman's spatial reading theory. In Fan's contention, the characters in these women writers' works form a new ethnic identity after moving to Taiwan due to everyday local encounters.

Research that followed Fan Mingru's, such as Wang Yuting [9], Hou Ruqi [5], and Xu Wanting [10], also began to question the cultural dominance or post-loyalist discourse. Most of these ensuing ideas use Stuart Hall's point of view in "Cultural Identity and Ethnic Diaspora." They believe the identification of cultural identity is not essence, but positioning, the result of continuous playing with history, culture, and politics [11]. Under this theoretical point of view, these studies suggest that although the mainland women writers of the 1950s had a strong Chinese identity; however, because they were in the different political contexts of Taiwan society, they must negotiate with local people, get involved with local events, and things at any time, so they placed themselves in a suitable position, making modest adjustments to their deep Chinese identity, and some even regarded Taiwan as a new hometown. Wang Yuting, Hou Ruqi, and $\mathrm{Xu}$ 
Wanting all believe that the cultural identity of these writers was shifting "between the two hometowns."

However, this phenomenon of "moving between the two hometowns" did not commonly occur among writers of that era. These studies consistently point out that because of the gender role, women writers have more opportunities in their daily lives to contact and negotiate with the local society, so they are more prone to have local identity. These studies all indicate that gender is a key factor in whether these discrete writers have local identity or not. But is gender a key factor in local identity? Qiu Gu ifen echoed David Der-wei Wang's argument that post-war woman writer literature rarely had cross-ethnic explorations or dialogues, let alone local identification. Most of the women writers' works still belonged to post-loyalist literature and were rarely related to the local society" [12]. Hou Ruqi's research also pointed out that the migration "between two hometowns" does not only occur in women, but also in some men [4]. It can be inferred from these studies that gender may be an important or even key factor in local identity, but it is not a necessary condition, let alone a sufficient condition. What is the most critical factor in local identity then? This research proposes the concept of "material life" in an attempt to respond to this is sue.

The "material life" referred to here is the "conditions of existence"; that is, the material conditions that a person must rely on to maintain his/her living, including food, clothing, housing, transportation, education, shopping and leisure, social networking, labor processes etc., and each of these specific life processes or content that each person experiences every day is the most important element forming this person's character. The so-called "character" here is, in the word Bourdieu, a person's "habitus." According to Bourdieu, the most basic tastes of a person, contains his/her taste for a place or a person, and his/her sense of justice, etc. These basic likes, dislikes or judgments are all part of one's personal habitus. Whether we like a place or not, or whether we identify with it, is determined by our deepest habitus unwittingly [13].

How is one's habitus determined? According to Bourdieu, one's class, meaning objective classifiable conditions of existence, and one's position in a structure of conditions of existence make up one's habitus which shows a person's distinctive system of schemes. When a person thinks and acts based on a particular system of schemes, he/she will have corresponding practices that constitute his / her distinctive life style. It's very consistent from the food you eat, the place you live, the car you drive, the friends you make, and the work environment. All of these have created a consistent habitus. Bourdieu said:

Systematicity is found... in all the properties with which individuals and group surrounded themselves, houses, furniture, paintings, books, cars, spirits, cigarettes, perfume, clothes, games, entertainments, only because it is the synthetic unity of the habitus, the unifying, generative principle of all practices [13:173].

Why did the Chinese that moved to Taiwan in the 1950s hold a strong Chinese identity? Why was Taiwan's local existence almost ignored? Why did they even describe Taiwan with negative emotions? In fact, the most important factor is that the mainlanders were not as the same as the Jewish discrete: The former were the ruling class and the cultural elites. Therefore, after they came to Taiwan, they formed a dense social network within themselves. Such a network not only provided a space for social interactions, but also the necessary material supplies, including food, clothing, daily necessities, living settlements, historical relics, newspapers and media, etc., without any contact or communication with the local society. In other words, although these mainlanders lived in Taiwan, their material life was Chinese, and they were tightly surrounded by Chinese mainlanders and objects. Therefore, most of them at the time did not understand or care about the lives of the local people. Many of them, even when traveling outside, were limited to a few of the places they were familiar with. For the living areas that really belonged to Taiwanese, such as towns, villages, alleys, te mple entrances, or any middle-lower class places they hardly visited, and even eyed them with disgust. Under this specific material living environment, their habitus and identity are understandable.

However, this provision of living conditions was not available everywhere. The best city of course was the capital Taipei, where the Chinese discrete would almost form their own world and be isolated from the outside world. Several other large cities, such as Kaohsiung, Taichung, and Tainan, were also pretty "ideal," but the physical conditions were not as good as Taipei's. As for other small local cities and towns, the mainlanders rarely lived. As can be expected, mainlanders living in these small regions may have to be forced to make frequent contact with the local people in order to meet the basic material living conditions. In this case, the habitus and identity of these people changed. This study found that the most obvious "shifting between the two hometowns" migrant wo men writers, such as Lin Haiyin, Xu Zhongyin, Zhong Meiyin, Zhang Shuhan, Ai Wen, etc., almost all lived in s mall towns, or lived in Taipei for a short time [4] [9] [10]. Although these writers were all female, this was certainly not the case for many other women writers living in Taipei. Although gender would assist them integrate into the local society as previously stated, the more critical factors were their places of residence and the material living or living conditions established by their places of residence. Next, I will analyze the identity of these mainland women writers through the material life of their places of residence. 


\section{Research Methods}

This research will focus on textual analysis, and the axis of analysis will start from the theme of this research, that is, how the place of residence of the discrete affects their material life arrangements, and how such arrangements shape and influence their personal cultural tastes and identities. I will divide the residence of the discrete people into two categories: the first category involves mainland women writers with long-term residence in Taipei, often recalling China's hometowns by means of memory; their living was also surrounded by all Chinese objects, and their social networks were also discrete literati from China. We need to see what is special about the cultural identity of this type of writers? The second type lived in small cities and towns. Because there were not many discrete people from China there, this type of writers was forced to make more contact and negotiations with local Taiwanese. We will examine what impact such a lifestyle has on their tastes and cultural identity? According to the inference of the above theoretical framework, the first type of women writers had a strong Chinese identity, ignored Taiwan's local life, and had a negative impression of Taiwan. The second type of writers, however, in addition to their maintaining a strong Chinese identity, they also slowly developed their feelings for Taiwan, and even thought Taiwan was another hometown, so they shifted "between the two hometowns."

There were actually many writers of the first type, and almost all writers of the 1950s belonged to this type. I will choose Liu Fang as the representative, mainly because her works have a lot of explanations about her life details, which can better reflect the theme of this study on "material culture," but it does not mean that she is special. In other words, she is just a typical example of that era. I will use Liu Fang's prose work, I and Others [14] as the main analysis object. This book is her description of her life. We can best see her various arrangements in daily life, including details of her everyday life, the choice of furniture, the decoration of the rooms, the memories of the hometown, and the description of Taiwan's scenery during various trips. In addition to textual analysis, I will also present her social life and networks from other literary reviews. I hope to fully cover all aspects of her "material life."

There are not many writers of the second type. Various studies all point to the following mainland wo men writers: Lin Haiyin, $\mathrm{Xu}$ Zhongpei, Zhong Meiyin, Zhang Shuhan, Ai Wen and several others [4] [9] [10]. Lin Haiy in was a native of Taoyuan, Taiwan, but grew up in Beijing since age 5, and settled in Taipei after returning to Taiwan since she was age 30 . But because she was Taiwanese, although there were many Beijing memories in her articles, there was still a lot of Taiwan content. Xu Zhongpei was from Changshu, Jiangsu. After living in Taipei for one year after coming to Taiwan at age 31 , she wrote I'm in Taipei, her first book to describe Taiwan. Since then, she often traveled abroad and settled in the United States and Canada after age 39. Zhong Meiyin was born in Peiping, moved to Nanjing at age 7, and moved to Taiwan at age 28. She settled in Suao, a small town in eastern Taiwan. She published the Memories of the Cold Spring at age 30, describing more than a year of living experience in Suao. When she was 34, she moved to Taipei for many years (including living in Kaohsiung for 2 years). After age 48, she settled overseas, living in such countries as Thailand, Singapore, and the US. Zhang Shuhan was born in Tongcheng, Anhui, and settled in Hsinchu when she came to Taiwan at age 20. She depicted Hsinchu in her various essays. Ai Wen was born in Suzhou and settled in Pingtung and Okayama when she came to Taiwan at age 26. Her work has a very detailed discussion of the lives of Taiwanese farmers and fishermen, and she was the writer deeply influenced by the bottom classes of Taiwan.

Among the second type of writers, I choose Zhong Meiyin as the analysis object. The main reason is that Zhong Meiyin settled in Suao after coming to Taiwan for six years, then moved to Taipei for more than 10 years, and finally settled abroad. Her diverse moving experiences in Taiwan, moving back and forth among small towns, big cities, and even abroad, allow us see clearly the relationship between identity and place of residence, and clarify the theme of this study. The texts analyzed include Memories of the Cold Spring during her Suao period, several articles from her other works after her relocation to Taipei and moving abroad. I will also use works of her counterparts to explore the details of their social interactions, so that we can have a richer understanding of her material life and condition of existence.

\section{Textual Analysis: Liu Fang}

I) Liu Fang represents the first type of mainland women writers. Liu was born in Jinan, Shandong, and moved to Beijing when she was 10 years old, but still traveled between the two cities. After graduating from university, the Sino-Japanese War broke out, so she volunteered to join the army. After the fall of the main land, she came to Taiwan with the government and settled in Taipei. Her debut article was "Escape from Peiping," recalling the civil war. After that, many of her articles contained more memories of Jinan and Beijing. Even her articles describing Taiwan would be mostly about her hometowns in mainland. She seemed very dissatisfied with the flowers, trees, and landscapes of Taiwan, so she often compared them with Chinese landscapes. Sometimes when recalling the scenery from the mainland, she also lamented the unsightly Taiwan scenery. When she traveled, she often felt there was nothing worthy of seeing, and she was even reluctant to get out of the car. 
Occasionally, she saw a favorite place, only because it reminded her of her hometown. Her room decoration and furnishings were almost a reproduction of classical Chinese interior decoration. Her daily contacts were all basically literati from China. We can say that Liu lived in a material world composed of Chinese objects or imagination. Below, I will analyze articles from $M e$ and Others. In the article "Non-Family Home" [14: 61-64], Liu wrote that in the first few years after coming to Taiwan, although she had a dwelling, she did not consider it her home. She would go out early every day and return home late, "go out a lock, go back a lamp." Although flowers bloomed outside the window, and indoor temperatures fluctuated, nothing mattered to her. She said, "I claim that I am a typical wanderer." She seemed to be ready to go back to the mainland at any time. Taiwan was only a temporary place of residence, so she couldn't care less about what happened around her. Ten years later, she finally decided to "settle down," so she began to set up her room to make it more like a home, hoping to settle down and no more wandering. She described the room in which she was furnished in the article "The Old Room" [14: 70-72]:

A small table with two drawers is placed across the window side, a bottle of ink, a tile on one side, and a small lamp with a green cover. ... Between the back wall of the chair are two freehand flowers, one is a lilac grape with light ink vines, and the other is loquats with golden leaves. ..."A genuine humble home," a piece of calligraphy written in four thick black bowl-shaped Weibei font on the jade version rice paper, is facing the mirror. Appreciating it from the mirror, this piece of calligraphy makes me feel uplifting. Looking at the' genuine humble room" [calligraphy], I murmured unconsciously: "Which one of us is not a sojourner in a dream-like life? Home is where the heart is." (translation mine)

Ink, ink stone, and rice paper are the tools of Chinese calligraphy and also the symbols of Chinese literati. Freehand flowers are a type of Chinese painting. The Wei Bei font is a calligraphy font which can almost be equated with "China." Liu used these typical Chinese objects and symbols to decorate her room, allowing herself to live in a material culture that symbolizes China, reminding her at any time that she was Chinese, and strengthening her identification with Chinese culture. The most interesting thing is what she wrote at the end of the article, "Which one of us is not a sojourner in a dream-like life? Home is where the heart is." Liu had wandered for ten years and finally settled down through the arrangements of her house objects. And it wasn't because she had lived in a place for a long time, she became familiar with it, and finally accepted the place home; it was rather after the Chinese-symbolic objects that she had thought about day and night were placed in her place of residence. She felt relieved and began to feel the place was home.
In addition to setting up her own home life, Liu also befriended other writers, especially authoresses. It must be emphasized here that in the 1950s, most Taiwanese literati were unable to write in Chinese because of Japanese education. Therefore, most writers at that time should be from mainland China. When Liu served as the editor-in-chief of "Literature World" in 1952 for six issues, she contacted many mainland writers. After she stepped down, she served as the host of "Art Window" of Education Radio [14:13]. After the establishment of the "Taiwan Provincial Women's Writing Association" in 1956, Liu actively participated in the "Women Writers' Birthday Party" curated by Lin Haiyin and they met at Lin's house once a month. In addition to these informal gatherings, at the time, the "Taiwan Provincial Women Writers' Writing Association" often went to the Kinmen frontline under the planning and subsidies of the government, or visited public construction sites to help promote national policies [9: 49-91]. These activities allowed Liu to establish a dense social network with other mainland writers, which was also very helpful for strengthening her Chinese cultural identity.

From the above material and social life, one can tell that Liu almost always lived in the Chinese habitus, naturally shaping her strong Chinese cultural identity. What's more, apart from the above specific living arrangements, Liu always re me mbered several ho metowns of China through writing so that she was surrounded by Chinese things and memories more closely. A mong these memories, we most often see her nostalgia for Beijing. In "Nine Recollections of the Old Capital" [14: 73-88], she recalled nine scenic spots in Beijing. In her memory of "Tao Ranting," she wrote: "I am not a native of old capital, but I have lived there for a long time, so every corner of the capital has an old dream that I deeply remember." The so-called "every corner" here is by no means an exaggeration. She not only missed and appreciated some famous natural landscapes or cultural landmarks in Beijing, she even felt places that ordinary people were unfamiliar with beautiful. Shichahai was exactly such a scenic spot. She wrote:

Beijing's Beihai, Zhonghai and Nanhai areas are in the core of Beijing where past dynasties were located, and today they are also the administrative centers. The lower reaches of these three seas have flowed out of Beijing, and are located in remote areas on the outskirts of the city. The scenery is not outstanding, so tourists are scarce. There is a market here only in summer. The singers are here, the comic talkers are here, the circus is coming, and so are the western films. In the summer, Shichahai becomes Beijing's second "overpass." Therefore, many literati have said that Shichahai had no place in the most elegant hall. However, Liu liked this town very much. She said, "Anyway, as long as I prefer a place, I would always find words to defend it. Regarding the Shichahai, no matter how those literati despise it, I would always insist it is like "a pretty girl 
of a humb le orig in" that has her own elegant style too." [14:82]. (translation mine)

Liu not only missed and praised Beijing scenery very much, but also compared it with Taiwan's scenic spots and laughed at Taiwan. For instance, after recalling the different scenery of Spring, Summer, Autumn, and Winter in Qionghua Island, and its rich changes, she wrote in the conclusion: "Here (referring to Taiwan), has only the bitter and disturbing mosquitos. I hereby proclaim, Formosa is worse than Qionghua Island "[14:78]. In the "Hutong" section, Liu described how the Beijingers in hutong were relaxed and calm, and she did not forget to scold how noisy Taiwan was, citing many examples:

The continuous autumn rain made mud all over the ground, which was a bit annoying, but the people passing by held up an u mbrella and lowered their heads to check the footprints of the predecessors... For a long time, the ancient city has been growing quietly. People here know how to enjoy quietness. Hutong is the home of a quiet home... in the clamorous world of Japanese wooden clogs (referring to Taiwan), I desperately wanted quietness. I, I couldn't help but miss the "hutong" [14:88]. (translation mine)

Besides her nostalgia for the Beijing, old capital, Liu is also full of nostalgia for her hometown, Jinan. In "Willows" [14: 45-47], she lamented that Taiwan had "four seasons like spring" throughout the year, and lacked seasonal changes. What it had all year round were some out-of-shape trees, such as the beard-like air-roots of banyan trees, the dull hollies, the awkward palms and coconut trees. One rarely sees the light cute trees such as willows. Therefore, she missed Jinan, a city surrounded by "four sides of lotus flowers, three sides of willows, and [it is] a city with mountains and half city lakes." Especially when spring comes, in front of "all families there are streams; every household has weeping poplars." She wrote in the conclusion:

Nowadays, my youth has gone prematurely. Life on the island is like stagnant water. Although I know pines and cypresses do not wither, and are evergreen, at the end of the year, they only retain the same old green color, and [they don't] even have the overflowing feeling of spring [14:47]. (translation mine)

Liu also totally denied Taiwan's flowering plants. Once, when she went to southern Taiwan to see phoenix trees, she was greatly fascinated by the green of the leaves and the red of the flowers, thinking that the red of the flowers of the phoenix trees was a true red, not crimson, not purple, not pink, and the green of the phoenix trees was also a true green." Moreover, she observed closely the arrangement of leaves and flowers in two colors, and she concluded that "there seemed to be no gaps between the leaves and flowers, and all one saw were only red and green." While being fascinated by the colors of those trees,
Liu suddenly felt "the two colors were very familiar. It turned out that they reminded me of a village girl's red short coat and green pants in my hometown" [14:35].

Liu rarely traveled in Taiwan. If she did, she visited with scholars arranged by the state. The main purpose was to write reports, promoting the infrastructure projects of the government, and strengthening people's determination to counterattack China. The trip depicted here was also carried out in this context. She first took the train out of Taipei and saw a green field outside the car, which attracted her, but she immediately said, "I'm not intoxicated by the infinite spring colors which would only remind me of the scenery outside the car window while in China." Apart from the scenery that made her remember mainland scenery, Liu's entire journey was very unpleasant. The main reason was that she didn't think Taiwan was beautiful. Compared with the mountains and rivers of the mainland, Taiwan's mountains and rivers were too plain. For example, she wrote about the Baihe Reservoir in Tainan: "The mountains are low, and the rivers are without charm. If you only travel among mountains and rivers, the long-winding journey is not worthwhile" [14:98].

Because she thought the mountains in Taiwan were ordinary, she hardly got off during the whole journey. In Dabei Lake in Kaohsiung, she only stayed in the car and thought that since all the flowers, trees, water, and bridges had been seen, it made no sense for her to get out of the car and bask in the sun. When she arrived at Kenting National Park, she did not get off either. When she arrived at Taitung Sizhongxi Hot Spring, she got off the bus but did not enter the hot spring. She felt that Taroko was quite majestic, but what moved her more was the veterans who built the Hengguan Highway: they came from China. When she finally arrived at Yang mingshan, she claimed that after she had seen the "big world, "meaning China, Yangmingshan was merely a tiny flower. [14:99]

II) The following is an analysis of the second type of mainland women writers, represented by Zhong Meiyin: Zhong came to Taiwan with her husband in 1948, landed in Keelung, and lived there for a year, then settled in the eastern town of Suao for six years. Suao was a s mall town located in a remote area in the east, with few mainlanders. Therefore, Zhong Meiyin's village life was very simple. Beside her daily housework, she raised chickens, ducks, grew vegetables, occasionally went to nearby markets, grocery stores, and interacted with local teachers or parents at her children's schools. She liked nature very much. Therefore, besides attending daily trivial matters, she spent more time observing nature, appreciating local natural environment. As a result, she had developed local identification with Taiwan. Below, I try to analyze texts from one of her books, Memories of the Cold Spring [15], published while she was living in Suao. Cold Spring is a well-known scenic spot in Suao. Zhong used Cold Spring as the book's title to express her love for Suao. In the book, 
she described a lot of her daily life during this period. I will examine her material life and living condition, and then analyze why she had gradually developed local identification with Taiwan.

In the article "My Life," Zhong wrote that she loved cleanliness, but she did not want to clean up all the rooms like a furniture company did - too clean to have a trace of humans. Therefore, her rooms were always simple, casual, and even a little messy. She described her home like this:

The bedroom walls, in addition to hanging magnified artistic family photos of playing on the beach in summer, do not have a problem to hang two clothes at a considerable distance. Although the bedding on all the beds must be square, beside the pillows, there may spread an unfinished novel or magazine. The bottle flowers on the small coffee table in the living room need to change the water every day, and the pile of Xiao Jing's (my child's name) treasures expand from inside of the table drawers to outside because the drawers are not big enough to accommodate those treasures-including a toy aircraft carrier, three waste batteries, two pieces of flint stones, two pieces of copper wire, a few batches of loquat leaves, and numerous pieces of bamboo used for water-skipping. Unless sometimes a "great" VIP would come to visit, I would not easily "invite" the treasures to the firewood room [15:53]. (translation mine)

In this article, we can see that the objects around Zhong's daily life were very different from those of Liu Fang. Here, there were no objects such as writing brushes, lotus roots, rice paper, pieces of calligraphy, and Chinese paintings that symbolized China. They were replaced by objects containing local elements of Suao or Taiwan, such as family portraits of playing on the seashore, children's toys, and some local plants. These objects had nothing to do with China, and neither was there a hint of her hometown in China. Therefore, these objects allowed her to live in real life, rather than go back in time. In addition to the room decoration, her daily housework also makes us more clearly see her material life and condition of existence. Take two of her articles--"The Story of a Chicken" and "The Egg Story" --as examples.

The "Chicken Story" was Zhong's first article after she came to Taiwan, describing that she bought a skinny hen from the market in preparations for the Dragon Boat Festival. However, after the hen entered the door, the big rooster next door was attracted by it and came to see it every day. The two chickens seemed to be in love. Zhong described the love between the two chickens in an anthropomorphic manner with the keenness of a writer. Because of the feelings for the chicken, she could not bear to kill the hen. As a result, there was not a chicken dish for Dragon Boat Festival dinner. However, there was a touching scene that shows the hen seemed to become part of the family: One day, the hen flew to the window and stretched her throat to sing. Zhong recalled what her mother had told her, and she knew that the hen was about to lay eggs, so she laid the chicken cage with straw and drove the hen into the cage. The cock followed. Zhong hurriedly called for her husband to come to take a look. She described the scene at the time:

The little hen lies silently on the grass, and the big rooster stand beside her silently with his chest raised, looking like a male guardian. Sometimes he crouches down to catch worms and feed them to the hen, and sometimes he walks around slowly, and seems to be the husband who is guarding his wife. "He is awaiting his child to be born. How responsible is he! How many among us can keep up with him!" I sighed and said, and my husband made a knowing smile to me [15: 29-30]. (translation mine)

From buying chickens and preparing dishes, taking chickens as part of the family and not being able to kill them, to the husband and wife watching the hens lay eggs, one can see Zhong had a high degree of interaction and connection with the surroundings. Zhong was living in the real world and interested in everything around her. Unlike most other mainland writers who came to Taiwan held a negative attitude toward Taiwan, Zhong often praised the scenery and objects around her. For example, she said that it was difficult to eat cauliflower on the mainland, but in Taiwan, it was everywhere. The peas in the main land had to be shelled, but the peas here could be eaten with skin and were sweeter. The short, fat loofah was easy to peel, the bitter gourd white and tender, and the natto soup even more delicious. The huge winter melon also amazed her [15: 100-101]. Indeed, from her sundry articles, one can tell that she truly enjoyed living in the present life.

Zhong's view of Taiwan also differed from many of her counterparts. Liu Fang, analy zed above, said that Taiwan's "mountains are low; rivers are flat." The flowers and trees were very ordinary, and not as beautiful as those in mainland China. However, Zhong was impressed by Taiwan's diverse and rich geographical landscapes. She stated that the "Eight Scenic Areas of Keelung" were fascinating and she wondered how people would dislike Taiwan [15: 100]? The spectacular waves on the east coast were better than Qiantang River's [15:42], and the majestic and magnificent Suhua Highway was even better than the Wujiang River:

This small island was so compact as a small sparrow with all its internal organs. I used to know that Taiwan not only had the magnificent scenery of the sea country, and also the beautiful scenery of the south of the Yangtze River. Now I discover that Taiwan and Yunnan both possess magnificent precipices. On the edge of the lofty ridge, a winding and sloping highway came out. . . The steep wall on the half side and the weak water on the other half side are like the Wujiang Station on the Sichuan-Qianjiang Road, but the vastness of the sea and the strange yet gorgeous clouds are far beyond what Wujiang can match [15:19]! 


\section{(translation mine)}

The above texts are records of Zhong's residence in Suao. She moved from Suao to Taipei in 1955, and the material and social life changed immed iately. In 1956, she accepted the invitation of Lin Haiyin, and edited the most important women's magazine at that time, the Women and Friends Monthly. Around this time, the Taiwan Women's Writing Association was also established, and Lin Haiy in held Women Writers' Birthday Celebration at her home once a month. Liu Fang and Zhong were important participants. The 823 Artillery Battle in Kinmen broke out in 1958, and the patriotic mainland writers often traveled to the Kinmen Army. In October of that year, Zhong participated in a group of writers invited by the China Youth Writing Association to visit Kinmen, and wrote a mixed chorus of "Hy mn for Kin men." In 1959, she visited Matsu with the Chinese Literature and Art Association. In 1963, as a lyricist, she visited Kinmen for the second time with the National Army Demonstration Band. In 1964, she hosted and produced the Taiwanese TV program "Mid-night Talks on Literature and Arts"[16: 45-86].

The above events show that Zhong's lifestyle has changed dramatically since she moved to Taipei. While in Suao, she was accompanied by chickens, ducks, vegetable, open-air market and grocery store clerks. In the surroundings of these people and objects, she carefully observed the details of them. From her personal delicate experiences, she lived a fun, meaningful local life, and gradually cultivated her feelings and identification with Taiwan. After moving to Taipei in 1955, things around her life were very different. She participated in various writers' associations, and the members of these associations were almost all from China. At this time, her attention to the local life here was greatly reduced, which was also reflected in her articles of this period. A few of her observations of Taiwan's locality had also begun to appear negatively. About nine years after she moved to Taipei in 1964, she published two collections of essays -- $A$ Journey to the Forts [17] and The Little Spring in October [18], which best represented her state of mind during this period.

A Journey to the Forts contains articles written nine years after she moved from Suao to Taipei. These articles differed greatly from her articles in Suao period. They were full of nostalgia for China and anti-communist sentiments because of her visiting the battlefields. They strengthened her identification with Chinese culture and reinforced her love for her motherland. On the contrary, her description of Taiwan's local life was much less, and her impression of Taiwan was mixed with many negative impressions. Like Liu Fang, she began to compare Taiwan with her Chinese hometown. Two articles, "Spring of Banqiao" [17: 251-255] and "At Age 40" [17: 25-29] are analyzed to show her psychological change.

In 1963, Zhong visited the recently completed catholic church in Banqiao and nearby places, including the Lin
Family Garden and the National Academy of Arts, so she wrote "The Spring of Banqiao." The catholic church in Banqiao was hailed as the largest and most beautiful catholic church in Taiwan at that time. Although Zhong praised it, she thought it was not big enough and too new. She believed whether it was a temple, church, or local place of interest, the longer the history, the better, and the older the better too. Therefore, she said that the Banqiao Catholic Church is not as good as the Sheshan Church in the suburbs of Shanghai. After visiting the Banqiao church, Zhong went on to visit the Lin Family Garden in Banqiao and the nearby National Academy of Arts According to her, the fact that the buildings of the National Academy of Fine Arts were lined in a horseshoe shape with a sports field in the middle showed how plain the school was. With only few flowers and plants, the campus was as barren as a desert. She thought of Hangzhou Academy of Fine Arts located in the West Lake. Compared to the West Lake, the Lin Family Garden was more like a bonsai. It was so small that it wouldn't even accommodate an art school. Due to its vastness, however, the West Lake could acco mmodate different styles of East and West. She concluded in this article:

The spring of Banqiao is lonely, with no trace of spring. Spring is in the land of my hometown, spring is in my heart. "No other waters could impress me for I've seen the vast seas. Having viewed majestic Wu Mountains, me other clouds can't please." Traveling all over Taiwan adds nostalgia, and my nostalgia is getting worse day by day. No matter how beautiful Banqiao Catholic Church is, it is not as fabulous as the one in Laoshan; the desert-like art school buildings make me even more nostalgic for West Lake. Spring is also better in my hometown" [17: 255]! (translation mine)

When Zhong lived in Suao, she was surrounded by local people and things, so she was fully integrated into the local life which made her intoxicated and happy, admiring the greatness and beauty of Taiwan. However, after moving to Taipei, there were too many "home towners" living in this big city. Her living conditions and material life had changed drastically. Every day she was in contact with China-related affairs or people. Her identity with China grew deeper, and so did her nostalgia for her hometown. But her feelings and identification with Taiwan were getting weaker, and many were even negative. This "Banqiao Spring" was a work about eight years after she moved to Taipei. Compared with Zhong in the Memories of the Cold Spring period, she turned into two different people. She compared every aspect of Taiwan with that in the mainland, and thought the latter was much more superior. She thought that spring was no longer in Taiwan, but in the land of her hometown. Similarly, in the article "At Age 40," she once again described Taiwan as a "small bonsai" comparing her childhood memories of China, and even claimed that she had homesickness: 
We have been squatting for too long in this small bonsai-like Taiwan. Every day I see these people, and hear these things. All the tourist attractions have been visited, all the local products have been tasted. And the movies are the same. I always feel too cramped and too boring. I actually suffer from nostalgia--I have never returned to the so-called hometown [17: 25-26]. (translation mine)

The Little Spring in October is also a collection of articles published after she moved to Taipei. A mong them, "Sundry Memories of Southern Traveling" [18: 84-95] best represents her mood change at this stage. This article records her views on visiting a certain A mitabha Temple in Chiayi, and she compared it with temples in China, showing her preference for her hometown temples:

Then I remember the joy of eating a friendship-binding meal at a nunnery when I was a kid. Whenever my mother had a fast or my siblings had measles, the temple would send over food. I liked quiet nunneries with half-closed brushwood doors and quiet courtyards, and I feel a bit cheesy about the golden and magnificently decorated Amitabha Temple. Here, even the huge Dali daisies in front of the temple are boasting an air of richness and nobility [18:91]. (translation mine)

But from June 1964, Zhong began a series of overseas travel. Perhaps because she was overseas, her views and feelings about Taiwan had changed again. At this time, Taiwan seemed to become the motherland in her mind. As she looked back at Taiwan, despite more critical, the emotion she showed was an anxiety and expectation of deep love, rather than a contemptuous attitude. At this time, her concerns fell entirely on Taiwan; China did not seem to be in her thinking and observation.

Zhong published Sea and Sky Trails 80 days after traveling around the world [19]. This is not a pure landscape-style travel journal, but a deep reflection of Taiwan through foreign countries. She believed the biggest problem in Taiwan was that it only sought to live by, hoped that everything would be fine after counterattacking China, and even used war as an excuse, thus creating a society full of perfunctory thinking and hoping for a fluke. Therefore, she pointed out in her preface painfully: "Time is the most ruthless. Instead of singing 'Counter-attack on the Continent,' why don't we first learn from the example of a first-rate country step by step today [19: 4-5]?" In that era full of the voice of "counter-attack on the mainland," Zhong's words were very unique, sharp, and focused. It was the so-called "feeling resentful when someone fails to meet one's expectation," and also showed her love and concern for Taiwan.

Zhong was impacted by foreign cultures due to her travels around the world. She repeatedly reviewed the shortcomings and deficiencies of Taiwan, and she rarely praised Taiwan in public. But as Xu Wanting [10: 130] points out: "In her severe condemnation, sarcastic critic is $\mathrm{m}$, and bitter persuasion, she is full of expectations for Taiwan society. Her criticis $m$ does not come fro $m$ the comparative psychology of 'foreign culture adulation,' or 'the grass is always greener on the other side.'" However, the experience of a rainy night in Hong Kong triggered Zhong's "Taiwan is good" emotional identity, and she even called Taiwan as "the motherland." She recalled:

The rain was getting heavy. I saw it through the window at $2 \mathrm{pm}$ that the ferry crossing stopped. No bus would run at $8 \mathrm{pm}$, but in fact, the wind and rain are not so big. I cannot help but take pride in Taiwan's buses. I told Hong Kong people Taiwan's buses would still be driving in bad weather. Even when they were no longer selling tickets, the buses were not limited by stop-by-stop parking. When the drivers saw a beckon on the road, they immediately stopped to take the passenger in because he/she is their compatriot. From here, I can tell that my own country is far lovelier [19: 32-33]. (translation mine)

In 1969, Zhong moved to Bangkok because of her husband's job. Her husband went to Bangkok 2 years earlier, and during his absence, because of her daughter's schooling, Zhong lived alone on the top floor of an apartment in Taipei. The family was divided into three places. The mood of being separated from her family made her particularly sensitive to the wind on the attic. Therefore, she called the Taipei place the Windy Attic. Whenever she listened to the wind and the rain, and couldn't fall asleep at night, she got up to read and write. After moving to Bangkok, although the home environment was splendid, she still missed the days of the Windy Attic, and her love for Taiwan was even deepened. Therefore, she compiled the articles written during that period into a book, Memos in the Windy Attic [20], and wrote a preface to it at her new residence in Bangkok: "The scenery is so beautiful outside the window. Yet I still love my Windy Attic, I love that dreary time, I love my work, and I love Taiwan, where I have lived for 20 years" [20: 3].

Zhong moved to Singapore in 1971, and after her husband's retirement in 1977, they settled in Los Angeles, USA. In 1980, Heaven Years [21] was published, recording her life in the United States. She returned to Taiwan from the US after a 13-year absence in 1982, and was admitted to National Taiwan University Hospital shortly afterwards. She died in 1984 at Linkou Chang Geng Hospital. Her husband carried her ashes back to the United States and placed them in Los Angeles. Heaven Years collects the details of her US life. In the article "My Heart Is in Taiwan" [21: 46-53], she said: "Remembering my life in Los Angeles, I really thank God for all these spiritual matters: literature, painting, music. . . Whatever I want, I dare not want, or I once dreamed of when I was a 
girl, are all given to me "[21:46]! This is what she called "paradise years." During this time, in addition to participating in church choirs, she also participated in the "Chinese Choir" composed of the overseas Chinese. She liked the church choir very much, but seemed to prefer Chinese songs more: Xiao Tairan's "There is No Salvation in the World," Lu Quansheng's "Please Drink Up." Lin Shengying's "Lift Your Hijab" and " "A River of Red, " Huang Youli's "Under the Silver Moonlight," all made her very much intoxicated. But Lu Quansheng's ensemble "Happy Meeting" made her fall into the memories of the past and felt the deepest. This song was adapted from a Taiwanese aboriginal folk song. Its long-sounding tones evoked her strong nostalgia. Such nostalgia was not for her hometown in mainland but Taiwan, where she had lived for more than 20 years. The following quotation is a bit long, but it represents her mood in a foreign land in her later years, and her feelings and identification with Taiwan:

There are many phrases in this song that are full of local flavor which I seem to be familiar with. Twenty years in Taiwan, I think that these phrases have already entered the subconscious unintentionally. They may have come from Sun Moon Lake's Pestle Song, or even rural Taiwanese opera. I wasn't prepared to remember them at the time, but they were buried deep in my heart. Therefore, when these songs suddenly appeared in our happy gatherings, how much of related past was evoked, and the sad and happy years that will never return, and my dear children. Yes, my children are all by my side, but they are not "them at that time" anymore. Suddenly, a deep nostalgia hurts my heart like liquor. Now I realize that even if I travel to the corners of the world, my heart is still in Taiwan, but I didn't realize it until the song came to wake me up [21: 52-53]. (translation mine)

The above is a textual analys is of Zhong's articles after she came to Taiwan with a diaspora of the mainland Chinese. Basically, we can divide this analysis into three stages: 1. Suao period: Suao is located in a remote corner of the east. Zhong was associated with local things, including natural landscapes and livestock. This complete localized living conditions and material life allowed her to cultivate her feelings and identity for the region. Therefore, her articles during this period are full of praise and appreciation of local things in Taiwan. 2. Taipei period: A large part of the main land elites came to Taiwan lived in this big city. These people not only possessed a high degree of cultural and political capital, but also formed a complete economic and survival habitus. In addition to a complete social network, they also lived a complete China-related material life. Such living conditions bred a strong Chinese identity which also substantially reduced their understanding and respect for Taiwan. 3. Period of living abroad: When living in a different place, Zhong was also stimulated by different cultures, yet her feelings for Taiwan seemed to have deepened. At this stage, Taiwan became the object of her homesickness, and her feelings towards China seemed to fade away. Her wanderings in the past between the two hometowns were officially settled at this time. Therefore, despite her "heaven years" in Los Angeles started in 1977, she returned to Taiwan in 1982 and died in Taiwan.

\section{Concluding Remarks}

Many Chinese who migrated to Taiwan in the $1950 \mathrm{~s}$ were not ordinary immigrants but a diaspora of Chinese elites. After they moved to Taiwan, they established their own living networks and rarely interacted with local Taiwanese. They had strong nostalgia and identity for the motherland. Moreover, they were not ready to take root and always wanted to return to their homeland. At this level, the Chinese diaspora in Taiwan is similar to the Jewish diaspora. However, one thing that is very different is that the Chinese discrete formed a ruling class and created the dominant culture. Not only could they maintain their original cultural identity, even the local Taiwanese voluntarily obeyed and accepted Chinese culture. These mainland elites almost paid no attention to local life, and they also harbored negative views on local things and people. This is the difference between the Chinese diaspora in Taiwan and other diasporas. Liu Fang's case is typical of the Chinese diaspora.

Although the dominant culture represented the political culture of that era to a certain extent, some recent studies [4], [9], [10] show that although the Chinese diaspora of that era used Chinese culture as their main identity, some of them already had quite a contact with local culture, and they began to consider Taiwan as their new hometown. These studies point out that these people are migrating "between two hometowns." Zhong Meiyin analyzed in this paper is representative of this type. Fan Mingru [7] even believes that these Chinese have taken Taiwan as their new hometown and established local cultural identity. These recent studies have raised the question: why under the Chinese dominant culture, some literati at that time could still establish local identity? The common answer to these studies is "gender." Simply put, due to the needs of female role-playing such as motherhood and being a wife, they have more frequent contact with local people and objects; therefore, they gradually cultivate their emotions and identity with Taiwan local things and people.

Although this study points out that gender is an important factor in local identity, it is not a necessary and adequate condition. The key factor for the mainland Chinese to cultivate their local identity, however, is their places of residence. Taipei was the largest city and capital. It gathered a large number of the mainlanders, so it fully formed an autonomous internal market, provided the necessary resources for social, economic, cultural, and 
political exchanges, and established a complete social network. Therefore, the Chinese living in Taipei were almost surrounded by people and objects related to China every day, forming a China-centered survival situation, or what Bourdieu calls "habitus." These material conditions were the key factors that shaped their Chinese identity. Simply put, culture is made of the material. However, other small cities did not have this material condition. The mainlanders living in these small towns were thus forced to contact and negotiate with local people, and their identity changed in the process.

In order to prove this hypothesis, this study takes Zhong Meiyin as the object, and analyzes in detail the different texts produced at different places of residence after she came to Taiwan. This study found that during the six years she lived in the small town of Suao, although she still had a strong identification with China, she had a high degree of affection for Taiwan's local life and had many positive evaluations of local people and things in Taiwan. However, when she moved to Taipei, she began to be trapped in Taipei's Chinese habitus, her Chinese consciousness came back, and her attention to Taiwan decreased significantly. She also liked to compare China with Taiwan, and she had a lot of negative comments on local people and matters. However, during her later period of living abroad, she missed Taiwan greatly perhaps because of being in a foreign country and being shocked by a different culture. Although she still criticized Taiwan a lot, it was not the same disdain mentality but rather out of her high expectations for Taiwan. During this period, she almost didn't mention China any more, and she always missed Taiwan, thinking of Taiwan as her motherland, and her only hometown. This is very different from the previous attitude of shifting "between the two hometowns."

Hall [11] points out that cultural identity is not a substantive issue; it is not eternally fixed in a certain essential past, but a continuous game between history, politics and power, a process of constant change. This study more specifically states that a key element of this change is the "place of residence." Different residences have different compositions, so they can also have a huge impact on the cultural identity of discrete people. As Giloy [22] points out in his article "Not where you come from, but where you are," the notion of "Where you are" has gradually replaced "Where do you come from," and has become a physical and mental assurance for immigrants. Zhong's ultimate identification was accomplished in a foreign land. Why "foreign land" becomes a catalyst for cultural identity is another issue worth exploring. Through the textual analysis of Zhong's works, this research allows us to see the material basis of cultural identity and the key role that "place of residence" plays in this changing process.

\section{REFERENCES}

[1] Ma, Laurence J. C., "Space, Place, and Transnationalism in the Chinese Diaspora," in Laurence J. C. Ma and Carolyn Cartier (ed.) The Chinese Diaspora: Space, Place, Mobility, and Identity. London: Rowan \& Littlefield Publishers, 2003.

[2] Skeldon, Ronald, "The Chinese Diaspora or the Migration of Chinese People?" in Laurence J. C. Ma and Carolyn Cartier (ed.) The Chinese Diaspora: Space, Place, Mobility, and Identity. London: Rowan \& Littlefield Publishers, 2003.

[3] Liao, Pin-Hui, Key Terms 2000, Taipei: Maiten, 2003, P. 79.

[4] Hou, Ru-qi, Between Two Hometowns: The Diaspora Narratives of Taiwanese Writers (1950-1987), Taipei: Lian-Jing

[5] Chang, Song-Sheng, Changes of Literal Field in Taiwan, Taipei: United Publishers, 2001.

[6] Wang, De-wei, Hou-yi-min Writings, Taipei: Maiten, 2007, P. 23-70.

[7] Fan, Mingru, "Taiwan New Homeland," in Mei Jialing ed., Gender Discourse and Taiwan Novels, Taipei: Maitian, 2000, P. 35-65.

[8] Friedman, Susan Stanford, "Telling Contacts," in Mappings: Feminism and the Cultural Geographies of Encounter, Princeton: Princeton University Press, 1998: P. 137-8.

[9] Wang, Yu-Ting, Women's Chorus: The emergence of Women Writers in Post-war Taiwan, Tainan: National Museum of Taiwan Literature.

[10] Xu, Wang-Ting, Writings About the Alien Home by the Women Writers in The 1950s: Hai-In Lin, Zhong-Pei Xu, Mei-In Zhong, Shu-Han Zhang, and Wen Ai, Master Theses of National Tsing-Hua University, Shin-Chu, Taiwan, 2008.

[11] Hall, Stuart, "Cultural Identity and Diaspora," in Diaspora and Visual Culture, 222-237, 2014.

[12] Chiou, kui-fen, "Literary Production Driven by Translation in Taiwan," in Chen Chan-chong et al (ed.) A History of Taiwan's Novels, Taipei: Maitian, 2003, P. 233.

[13] Bourdieu, Pierre, Distinction: A Social Critique of the Judgement of Taste, Cambridge: Harvard University Press, 1984.

[14] Liu, Fang, Me and Others, Taipei: San-min, 1971.

[15] Zhong, Meiy in, The Memories of The Cold Spring, Taipei: Chong-guang, 1951.

[16] Wang, Yu-Ting (ed.), Zhong Mei In: A Collection of Research Materials for Contemporary Writers, Tainan, National Museum of Taiwan Literature, 2014.

[17] Zhong, Meiyin, A Journey to the Forts, Taichuan: Guang-Qi Publishers, 1964.

[18] Zhong, Meiyin, The Little Spring in October, Taipei: Wen-xing, 1964. 
[19] Zhong, Meiyin, Traveling to Far-away Lands, Taipei: The Great China Publishers, 1966.

[20] Zhong, Meiyin, Memos in the Windy Attic, Taipei: San-Min, 1969.

[21] Zhong, Meiy in, Heaven Years, Taipei: Huang-guan, 1980.

[22] Gilroy, Paul, "It Ain't Where You're From. It's Where You're At....: The Dialectics of Diasporic Identification," Third World Perspectives on Contemporary Art \& Culture. 13: 3-16 